Check for updates

The BMJ

Cite this as: BMJ 2021;375:n2993 http://dx.doi.org/10.1136/bmj.n2993 Published: 6 December 2021

\title{
EXCLUSIVE
}

\section{Covid-19: Refugee doctors join NHS through innovative scheme}

\section{It's nearly a year since health leaders in England launched a new pathway to enable doctors from abroad to work in the NHS. Elisabeth Mahase reports on its progress}

\section{Elisabeth Mahase}

The medical support worker (MSW) scheme, introduced by NHS England to boost the workforce during the covid-19 pandemic, has enabled refugee and international doctors who may otherwise have been unable to use their skills to join the NHS.

The BMJ understands that over 400 doctors have so far been given roles in the NHS in England through the MSW scheme. The programme has enabled doctors who don't have General Medical Council (GMC) registration-either owing to retirement or because they are from other countries-to work in the NHS under supervision. Their tasks include assisting clinical staff in delivering patient care, carrying out clinical observations, performing diagnostic or therapeutic procedures, undertaking clinical audits, and running quality improvement projects.

The GMC registration process can take years for overseas doctors and can be especially difficult for refugee doctors, who may have been out of work for years before applying. But the support worker scheme gives doctors a paid role to enable them to restart their medical careers and learn how the NHS works, while also boosting the workforce at a time when the healthcare system is under intense pressure.

\footnotetext{
The story of Mo, a medical support worker

Mo grew up in Aleppo, a city in northwestern Syria where he studied medicine and started his training as a doctor. In 2016, five years into the Syrian war, Mo left his home country and travelled to the UK over nearly a year. It then took him another eight months to gain refugee status. However, after years out of practice he still faced a long journey to find his way back into medicine.

Mo says that the lack of practical experience is one of the main barriers for refugee doctors wanting to work in the UK. "I don't know any refugee doctors who have been able to pass the practical exam [required for GMC registration] within two or three years, because we don't have the experience and we don't get the opportunity to get the experience," he told The BMJ.

But even after GMC registration, Mo says that the lack of practical experience in the UK's health system still counts against refugees. "I know some doctors who have been here for eight years but are not able to practise medicine, even though they managed to get their GMC registration two years ago, and they still can't find a job."

This is where Mo thinks that the medical support worker role will make a difference. "It's the perfect change to the system," he says. After starting work as a medical support worker earlier this year at George Eliot Hospital in Warwickshire, Mo says that he can now do everything a junior doctor can-under clinical supervision-and that he is gaining the vital experience he needs to pass his practical exam (PLAB 2). On top of this, the hospital has
}

said that once he gains GMC registration it will offer him a full time position as a senior house officer.

In December 2020 NHS England wrote to medical directors around the country, ${ }^{1}$ announcing €15m of funding to support the "short term recruitment of up to 1000 doctors as MSWs" as part of plans to relieve winter and pandemic pressures on the NHS. This funding has been made available to trusts to cover the full salary of any MSWs they employ, 0.2 whole time equivalent consultant time per trust for educational supervision, and £250 per employee for training costs. The funding for the scheme has been guaranteed until March 2022.

\section{Midlands project}

In the Midlands 58 MSWs have so far been employed across 13 local employers (12 at NHS trusts, one in a GP federation), including 16 refugees. Of the refugee doctors, three have already gained GMC registration and progressed to NHS training roles.

When starting out, the Midlands team worked with local workforce and medical leaders to understand what work needed covering and then built individual roles around those needs. While advertising these roles they also reached out to refugee organisations to find potential applicants, as they saw this paid role, which comes with a salary of around $€ 30000$ a year, as a perfect opportunity to enable international and refugee doctors to work in the NHS.

The Midlands team has also provided support for the MSWs, including a mentoring scheme linking the refugee and international doctors with retired doctors who can give them guidance and advice as they progress through GMC registration and into the NHS permanently. All medical support workers are required to meet English language requirements.

Daniel Smith, a respiratory specialist registrar and one of the Midlands team leads, told The BMJ that working on the scheme had been "extremely rewarding," especially after hearing some of the stories of the refugee doctors and then seeing them go on to work as doctors in the NHS after completing their support worker roles.

"The medical support worker role has proved to support organisations during a period of unprecedented demand and has fantastic potential to support many doctors from a range of backgrounds into their first role in the NHS and hopefully a long and successful career," he said. "The programme has been very successful in the Midlands, with a broad 
range of doctors undertaking innovative roles in acute, mental health, and primary care trusts, and now there is great progress in ensuring that the role becomes sustainable."

Smith said that the two main challenges of rolling out the scheme were raising awareness of what MSWs can do within the departments and ensuring clinical supervision.

Sailesh Sankar, a consultant in endocrinology and diabetes at University Hospitals Coventry and Warwickshire NHS Trust, said that the scheme had been "helpful for both the workers and wider NHS."

He told The BMJ, "It has enabled the doctors to settle and understand the NHS system and familiarise themselves with the working arrangements and culture. Some of them have even been successful in getting a training post.

"For the healthcare system, they have added value in supporting tasks, including quality improvement projects and supporting patient care. It is likely that this cohort will have an added benefit when they enter into a training programme, as they will undoubtedly be better prepared for working in the NHS."

\section{Workforce shortages}

Before the covid-19 pandemic, doctors and health leaders had long been warning that a substantial increase in workforce numbers was needed to meet growing demand. ${ }^{2}$ The pandemic has exacerbated this issue, and the remaining exhausted staff are now expected to tackle winter pressures, covid-19, the backlog from cancelled treatment, patients who delayed seeking healthcare because of the pandemic and are likely to be more seriously ill now, and screening and vaccination programmes. ${ }^{3}$

The Midlands team believes that the MSW scheme could be part of a longer term workforce solution if its funding is extended. Jazz Singh, the medical workforce senior programme manager for the Midlands who is heading up the programme in the region, said that "more of the same is not an option" for tackling the NHS's workforce challenges.

"The new medical support worker role provides just the innovation needed to help the NHS address current workforce pressures and in addition can potentially provide us with future NHS doctors," he said. "This is a unique opportunity to help augment clinical teams with this new role, helping in some way to meet the challenges."

\section{Correction: We amended the title of this story on 6 December 2021 because the wording} was potentially misleading.

1 NHS England. Additional funds to support winter workforce pressures. 15 Dec 2020. https://www.england.nhs.uk/wp-content/uploads/2020/12/BW338-Letter-re-winter-workforce.pdf

2 Edwards N, Palmer B. A preliminary workforce plan for the NHS. BMJ 2019;365:14144. doi: 10.1136/bmj.l4144 pmid: 31186233

3 Mahase E. Winter will be "exceptionally difficult" for NHS irrespective of covid, Chris Whitty warns. BMJ2021;375:n2534. doi: 10.1136/bmj.n2534 pmid: 34663567

This article is made freely available for use in accordance with BMJ's website terms and conditions for the duration of the covid-19 pandemic or until otherwise determined by BMJ. You may use, download and print the article for any lawful, non-commercial purpose (including text and data mining) provided that all copyright notices and trade marks are retained. 